\title{
X-Ray Microanalysis at High Accelerating Voltage Detecting Aluminum Accumulation in Mouse Kidney after Short-Term Aluminum Administration
}

\author{
Kiyokazu Kametani ${ }^{1}$, Kayo Suzuki ${ }^{1}$ and Tetsuji Nagata ${ }^{2,3}$ \\ ${ }^{1}$ Research Center for Instrumental Analysis, Shinshu University and General Research Laboratory, Shinshu University School of \\ Medicine, Matsumoto 390-8621, Japan, ${ }^{2}$ Department of Anatomy and Cell Biology, Shinshu University School of Medicine and \\ ${ }^{3}$ Department of Anatomy and Physiology, Nagano Women's Jr. College, Nagano 380-0308, Japan
}

Received March 4, 2003; accepted March 25, 2003

Elemental analysis on Al was carried
out by energy dispersive X-ray (EDX)
microanalysis using high accelerating
voltage at $300 \mathrm{kV}$ with high permeability
in thick samples at $1 \mu \mathrm{m}$ thickness ob-
tained from $27 \mathrm{ddY}$ mice administered
with Al for 1 to 17 weeks. The quantities
of Al detected in the lysosomes of the
convoluted tubule cells of the kidney did
not relate to the Al administration period.
A significant difference in the quantity of
Al between the administration group and
the non-administration group was found
by stochastical analysis with two-way
factorial analysis of variance followed

by Fisher's PLSD for multi-comparison. However, the quantities of Al detected in the nuclei of the proximal convoluted tubule cells of the kidney suggested a correlation with the Al administration period. EDX microanalysis using thick sections and high accelerating voltage was useful in detecting the Al accumulated in the lysosomes and nuclei of the kidney cells. The EDX microanalysis was able to detect Al accumulated in the lysosomes and clarify the transitional changes of the quantities of Al detected during a short-term excessive Al administration.

Key words: aluminum, EDX microanalysis, high voltage electron microscopy, lysosome, mouse kidney

\section{Introduction}

Aluminum is one of the common elements often found in our daily lives. Many papers report that Al causes pathological and toxicological influences upon the living body $[29,35,36]$. Aluminum is also suspected to cause such diseases as dialysis encephalopathy, which is due to dialysis treatment of patients suffering from renal failure [7]. The treatments for renal deficiency in patients are hemodialysis and anti-inflammatory or antacid drugs. It is well known that hemodialysis liquids and anti-inflammatory or antacid drugs contain $\mathrm{Al}$ gel. After the use of such hemodialysis liquids and drugs were stopped, complications from dialysis encephalopathy decreased. As a result, Al was regarded as the etiology of dialysis encephalopathy $[7,17,29]$. In recent years, it is of concern that acid rain dissolves Al from the earth's surface into bodies of water due to changes in the earth's environment. The influences of Al manifest not only

Correspondence to: Kiyokazu Kametani, Ph.D., Research Center for Instrumental Analysis, Shinshu University, Matsumoto 390-8621, Japan. in renal failures on dialysis but also in fish and plants [6]. As a result, $\mathrm{Al}$ dissolved in acidic water is estimated to be absorbed in the living bodies of animals and plants. It is important to clarify the influence of excess $\mathrm{Al}$ accumulation taken into the living body through drinking water. Heavy metals such as cadmium $(\mathrm{Cd})$ and copper $(\mathrm{Cu})$ are well known to accumulate in cells and cause morbid influences in the living body [13, 30, 37]. The detection of such poisonous metals in cells and tissues has not only been carried out with biochemical methods [27], but also with histochemical and cytochemical techniques [13, 32, 33]. However, the histochemical studies on $\mathrm{Al}$ taken into the living body and its accumulation in cells are still insufficient. Metal accumulation, such as of $\mathrm{Cu}$ and $\mathrm{Cd}$, in the living body is supposed to cause such toxic symptoms as kidney failure [16, 30, 35]. The problem of $\mathrm{Al}$ accumulation at the present time is to clarify the influence of $\mathrm{Al}$ absorption with small quantities for long durations in living bodies. Usually, the detection of elemental accumulation in a cell is measured by examining via biochemical methods, the proteins and enzymes which are bound to the elements in serum. The specific protein caused by metal accumulation increased in the tissues, 
blood, and urine $[15,18]$. It was reported that the metallothionine protein was related to the accumulation of $\mathrm{Cu}$ in the cytoplasm of the brain, liver, duodenum, and kidney when cell degeneration occurred from metal accumulation $[14,19]$.

Elemental analysis study by energy dispersive X-ray (EDX) elemental microanalysis allowed observation of ultrastructural changes at the electron microscopic level and simultaneous qualification and quantification of an element in situ. Using biological specimens, EDX elemental analysis was carried out with ultrathin sections at $0.1 \mu \mathrm{m}$ thickness and conventional electron microscopy with accelerating voltages of 80-100 kV [37]. The sections submitted to EDX elemental analysis should be thin because the electron beam of conventional electron microscopy can transmit only thin sections. However, it is thought that using thicker sections is more advantageous because they contain more elements [20, 21]. EDX microanalysis using high accelerating voltage at $300 \mathrm{kV}$ and thicker sections of $1.0 \mu \mathrm{m}$ thickness demonstrated that $\mathrm{Al}$ conjugated with proteins like metallothionine, concentrated in lysosomes of digestive organs such as the duodenum, liver, and kidney [12]. In the study, the administered $\mathrm{Al}$ was detected in lysosomes with a high electron density in the macrophages of the duodenal mucosa, the hepatocytes of the liver, and the proximal convoluted tubule cells of the kidney.

In order to elucidate the relation between the quantitative changes of absorbed $\mathrm{Al}$ in the kidneys and postnatal development and aging of experimental animals, we attempted to study the elemental analysis of $\mathrm{Al}$ using high accelerating voltage at $300 \mathrm{kV}$ with EDX microanalyzer, utilizing its high permeability in thick sections according to the previous experiment, and to observe the morphological changes in the lysosomes of convoluted tubule cells in the kidneys after excess oral administration with Al-chloride to mice for short-term periods from 1 to 17 weeks during the aging process.

\section{Materials and Methods}

\section{Animals}

Nine groups of ddY strain male mice, each consisting of 3 littermates, from postnatal week 1 to $3,5,7,9,11,13$, 15, and 17, (total 27 individuals) were used. The embryonic ages of mice were based on observation of the vaginal plugs of the female mice (vaginal plug=day 0 ) after mating. The pregnant mice were housed under conventional conditions, fed with normal mice chow (Clea CE2, Tokyo, Japan) with access to deionized water ad libitum (Japan SLC. Inc., Hamamatsu, Japan) until they were purchased and transferred to our laboratory on embryonic day 14 . Then, they gave birth on embryonic day 18 , when the postnatal ages of the newborn baby mice were counted as postnatal day 0 . Thus, postnatal day 1 to week 17 mice, each consisting of 3 littermates, (total 27) were adminstered orally with deionized water containing $2 \% \mathrm{AlCl}_{3}$ (aluminum chloride, Nakarai Chemical, Kyoto, Japan), at pH 2.5, ad libitum immediately after birth until 17 weeks. In case of newborn mice at postnatal day 1 to 14 , the animals were administered with deionized water containing $2 \% \mathrm{AlCl}_{3}$ by means of mouth tubing once a day and fed with mother's milk ad libitum. After delivery the mothers were also fed with deionized water containing $2 \% \mathrm{AlCl}_{3}$ ad libutum and allowed to nurse the baby mice ad libutum until postnatal week 3. After each administration period of 1, 3, 5, 7, 9, 11, 13,15 , and 17 weeks, two mice were sacrificed under ether anesthesia and the kidneys were removed, cut into several small pieces, and fixed. As the negative control without administration, nine ddY strain mice were administered orally with deionized water for the same administration period (from 1 to 17 weeks), sacrificed under ether anesthesia and the kidneys were removed, cut into several small pieces, and fixed at respective periods. All the procedures used in this study relating to animals were in accordance with the protocol reviewed and approved by the guidelines of the Animal Research Committee of Shinshu University School of Medicine as well as the principles of laboratory animal care (NIH Publication No. 85-23, revised 1985).

\section{Morphological observation}

For light and electron microscopic morphological observation, tissues were fixed in $2.5 \%$ glutaraldehyde in phosphate buffer, $\mathrm{pH} 7.4$, at $4^{\circ} \mathrm{C}$, for $2 \mathrm{hr}$ and post-fixed in $2 \%$ osmium tetroxide in the same buffer at $4^{\circ} \mathrm{C}$, for $1 \mathrm{hr}$. Then, the tissues were dehydrated in a graded series of ethanol, substituted with propylene oxide, and embedded in epoxy resin (Epok 812, Oken, Tokyo, Japan). For light microscopic observation, thick sections were cut at $3 \mu \mathrm{m}$ thickness on an OmU4 ultramicrotome (Reichert-Jung, Vienna, Austria), stained with $1 \%$ toluidine blue (Merck, Frankfurt, Germany) in phosphate buffer at $\mathrm{pH} 7.4$ and observed with a light microscope (Nikon Optiphot-2, Nikon, Tokyo, Japan). For electron microscopic observation, ultrathin sections were cut on the same ultramicrotome (Reichert-Jung, Vienna, Austria) at $0.1 \mu \mathrm{m}$ thickness, mounted on copper grids (VECO, Eerbeek, Netherlands), and stained with uranyl acetate and lead citrate. Specimens were then observed with a conventional TEM, JEM-1200EX (JEOL, Tokyo, Japan) at an accelerating voltage of $80 \mathrm{kV}$.

\section{EDX microanalysis}

For EDX elemental microanalysis with electron microscopy, tissues were fixed only in $2.5 \%$ glutaraldehyde in phosphate buffer, $\mathrm{pH} 7.4$, at $4^{\circ} \mathrm{C}$, for $2 \mathrm{hr}$, dehydrated in a graded series of ethanol, substituted quickly with propylene oxide, and embedded in Technovit VL7200 resin (Meiwa, Tokyo, Japan). This Technovit VL7200 resin did not include chlorine and was suitable for elemental analysis. For elemental analysis of $\mathrm{Al}$, thick sections were cut at $1.0 \mu \mathrm{m}$ thicknesses on the same ultramicrotome, mounted on nylon grids (VECO, Eerbeek, Netherlands), stained with uranyl acetate, and coated with a thin carbon layer. The sections were then observed and analyzed in a high voltage TEM, JEM-4000EX (JEOL, Tokyo, Japan) at an accelerating 

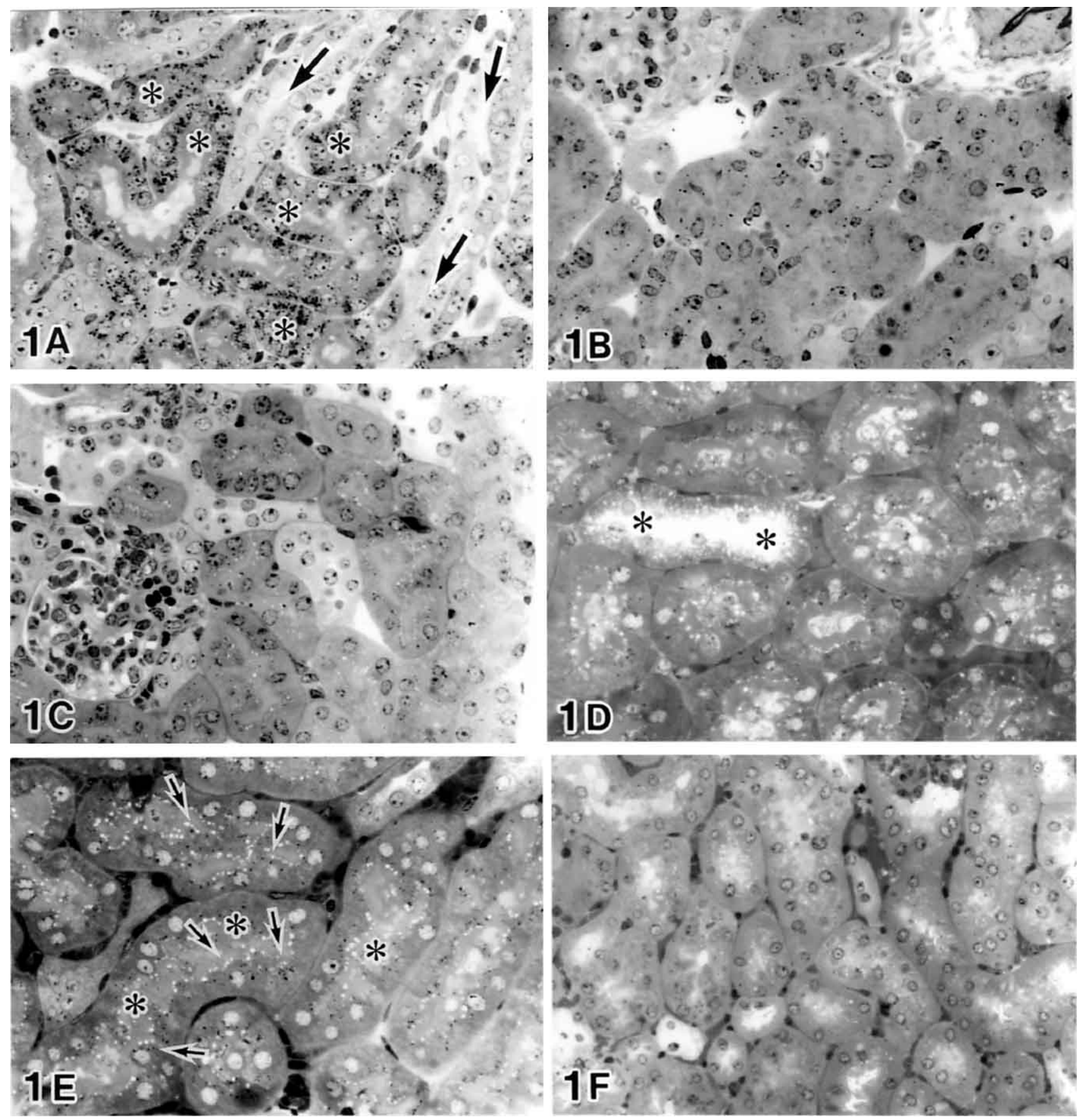

Fig. 1. Light micrographs of the kidneys of mice either administered without (A) or with $\mathrm{Al}$ for certain periods (B-F), fixed in glutaraldehyde and osmium tetroxide, embedded in Epok, sectioned at $3 \mu \mathrm{m}$, and stained in TB. (A) The kidney tissue of a mouse administered with Al for 1 week. There were two types of tissues observed in the convoluted tubule cells of the kidney. One had many darkly stained granules $(*)$, while the other was stained brightly (arrows). (B) The kidney tissue of a mouse administered with Al for 5 weeks. The number of darkly stained granules decreased as compared to that of mice administered Al for 1 week. (C) The kidney tissue of a mouse administered with Al for 9 weeks. The number of dark stained granules increased again. (D) The kidney tissue of a mouse administered with Al for 13 weeks. Many darkly stained granules and apical vesicles were seen in the same cells of the convoluted tubule. In addition, the degenerative changes of swelling cytoplasm in the proximal convoluted tubule cell were seen $(*)$. (E) The kidney tissue of a mouse administered with Al for 17 weeks. Many darkly stained granules and apical vesicles were seen in the same cells of the convoluted tubule (arrows). Cell degeneration was seen with the disappearance of the nucleus in the convoluted tubule cells $\left(^{*}\right)$. (F) The kidney tissue of a normal control mouse fed on diet without $\mathrm{Al}$ administration for 17 weeks. Darkly stained and large granules were not observed in the proximal convoluted tubule cell. However, a few apical vesicles were seen in the proximal convoluted tubule cell. $\times 200$. 
voltage of $300 \mathrm{kV}$, equipped with a TN-5400 EDX microanalyzer (Tracor-Northern, Wisconsin, USA). The section thickness at $1.0 \mu \mathrm{m}$ and the accelerating voltage at $300 \mathrm{kV}$ were decided according to the data obtained from the relationship between accelerating voltages and $\mathrm{P} / \mathrm{B}$ ratios of $\mathrm{Al}$ contained in the macrophages of mouse small intestine in sections of various thicknesses, from 0.1 to $2.0 \mu \mathrm{m}$, as was reported previously [12]. Electron beams (beam current $93 \mu \mathrm{A})$ were focused onto the highly electron-dense lysosome and nucleus in each proximal convoluted tubule cell of the kidney. Electron beams were continuously irradiated to a small spot (diameter $200 \mathrm{~nm}$ ) and the emitted X-ray was analyzed with specific EDX spectra counts for $100 \mathrm{sec}$ within $25 \%$ dead time. The Al spectrum was counted at the peak of $\mathrm{Al} \mathrm{K}-\alpha$ at $1.49 \mathrm{KeV}$ energy and a sub-area was calculated at $\pm 0.1 \mathrm{KeV}$. The quantification of $\mathrm{Al}$ was measured by calculating a peak (P) to background (B) ratio. Background was counted within a range of $4.6-4.8 \mathrm{KeV}$, which was not measured at the specific peak in a biological specimen. The relative concentration of $\mathrm{Al}$ at each administration period was represented by the mean $\mathrm{P} / \mathrm{B}$ ratio obtained from 10-15 randomly selected lysosomes and nuclei. The data were calculated as means \pm standard deviations. Significant differences between the Al administration and the duration of administration were stochastically analyzed with repeated measurement using two-way factorial analysis of variance followed by Fisher's PLSD for multicomparison.

\section{Results}

\section{Light microscopic observation}

Upon observing the kidney tissues of mice that orally administered with $\mathrm{AlCl}_{3}$ by light microscopy, many darkly stained granules were found in the proximal convoluted tubule cells stained with toluidine blue (TB stain). The results of these observations at each administration period from 1 to 5, 9, 13, and 17 weeks are shown in Figure 1. At 1 week of Al administration, two types of structures were observed: one in which the convoluted tubule cells contained dark granules and the other in which the convoluted tubule structures were seen brightly in the kidneys of the $\mathrm{Al}$ administered mice (Fig. 1A). In the portions where the convoluted tubule structures were formed, the proximal convoluted tubule cells and the distal convoluted tubule cells were clearly distinguished by light microscopy. However, those structures showed no difference from the normal control mice 1 week after birth without $\mathrm{Al}$ administration. In the early newborn period, the proximal convoluted tubule cells of the Al administered mice contained many darkly stained granules, which were supposed to be the active reabsorption in the kidney. At 5 weeks $\mathrm{Al}$ administration, the numbers of black granules in the proximal convoluted tubule cells had decreased and the intensity of TB staining weakened compared to the period after 1 week administration (Fig. 1B) as well as with normal control animals at postnatal 5 weeks. At 9 weeks Al administration, the number and intensity of the black granules in the proximal convoluted tubule cells increased again (Fig. 1C). At the same time, small vesicles in those cells increased in number around the urinary lumen (Fig. 1C). Such changes were not found in the normal control animals at postnatal 9 weeks. At 13 weeks Al administration, the interstitial regions in the tubule cells disappeared as a result of proximal convoluted tubule cells that degenerated with swelling changes (Fig. 1D). In addition, nuclei of the proximal convoluted tubule cells partially disappeared and the number of the granules increased to a level greater than that of the previous period at 9 week administration. The brush borders of the proximal convoluted tubule cells were clearly observed in the apical cytoplasm, though they appeared brightly because of their cytoplasmic degeneration. Such changes were not found in the normal control animals at postnatal 13 weeks. At 17 weeks, many black granules and apical vesicles were observed in proximal convoluted tubule cells (Fig. 1E). The interstitial tissues in the tubule cells disappeared because of degeneration. The degeneration of tissue structures was also observed in the kidney tissues at 17 weeks administration (Fig. 1E). Those changes were not found in the normal control animals without $\mathrm{Al}$ administration at postnatal 17 weeks (Fig. 1F).

\section{Electron microscopic observation}

The results obtained from ultrastructural observation on proximal convoluted tubule cells of mouse kidney tissues at 1 week after $\mathrm{Al}$ administration as well as the negative control without $\mathrm{Al}$ administration are shown in Figure 2. In the negative control animals that were not administered with $\mathrm{Al}$, the lysosomes with high electron densities were fewer in number and smaller in size (Fig. 2A) than the experimental animals that were administered with $\mathrm{Al}$ (Fig. 2B). Apical vesicles were seen in the portion near to the urinary lumen in the proximal convoluted tubule cells of both the administered and un-administered animals. At 1 week after Al administration, many large sized lysosomes with high electron

Fig. 2. Electron micrographs of the proximal convoluted tubule cells of mice, either administered without (A) or with Al for 1 week (B), 5 weeks (C), 9 weeks (D), 13 weeks (E), and 17 weeks (F), fixed in glutaraldehyde and osmium tetroxide, embedded in Epok, sectioned at $0.1 \mu \mathrm{m}$, and stained with uranyl acetate and lead citrate. (A) A very small lysosome (arrow) and small vacuoles (arrow head) were seen near the urinary lumen. (B) Large lysosomes (arrow) and vacuoles (arrow head) were seen around the nuclei. (C) Large vacuoles (arrow head) were seen around the urinary lumen. (D) Many lysosomes (arrow) and small vacuoles (arrow head) were seen near the urinary lumen. $(\mathbf{E})$ The number of large $(*)$ and small (arrows) lysosomes increased in the proximal convoluted tubule cells. Cellular degeneration $\left({ }^{* *}\right)$ was also seen in the proximal convoluted tubule cells. (F) Large $(*)$ and small (arrows) lysosomes were seen in the proximal convoluted tubule cells. The large lysosomes were seen in the sites where the nuclei are usually located in the proximal convoluted tubule cells. Bars $=2 \mu \mathrm{m}$. 

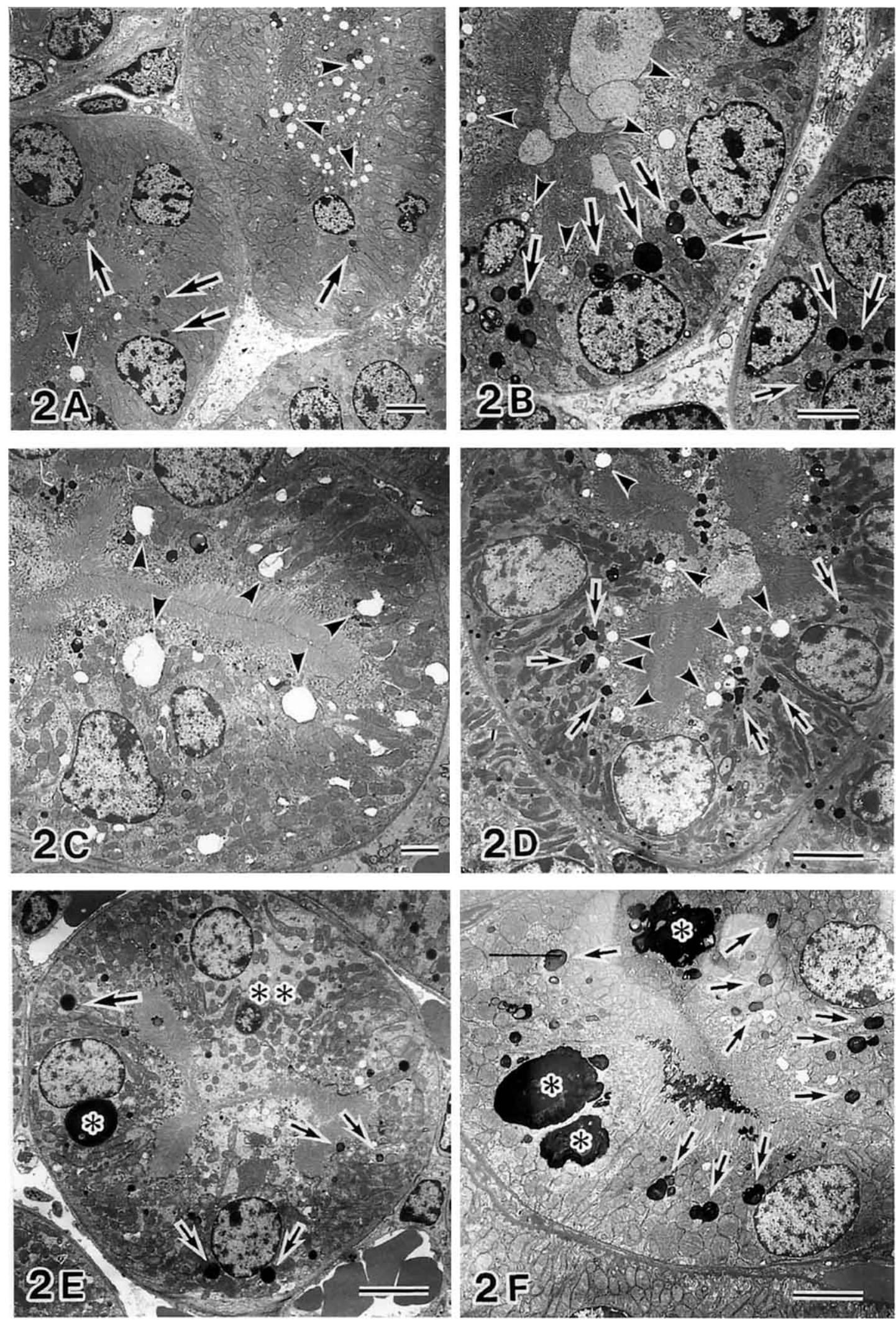

Fig. 2 
densities were observed (Fig. 2B). In addition, there were large vacuoles in the proximal convoluted tubule cells in the cytoplasm near to the urinary lumen, while a small vacuole was observed in the portion surrounding the nucleus. The results obtained from the ultrastructural observation of the proximal convoluted tubule cells of mice kidneys at each $\mathrm{Al}$ administration period from newborn to 5, 9, 13, and 17 weeks are shown in Figures 2C, D, E, and F, respectively. At 5 weeks $\mathrm{Al}$ administration, the number of the lysosomes with high electron densities decreased (Fig. 2C) as compared to that of 1 week $\mathrm{Al}$ administration (Fig. 2B). The size of the lysosomes administered with $\mathrm{Al}$ for 5 weeks was observed to be smaller than the size of lysosomes administered for 1 week. Nevertheless, the numbers of various-sized vesicles at 5 weeks $\mathrm{Al}$ administration were observed more than those at 1 week administration period. Observations by high power magnification revealed that the structures of some lysosomes contained heterogeneous bodies with high electron densities, which should be classified as heterolysosomes in the proximal convoluted tubule cells at 5 weeks administration. At 9 weeks $\mathrm{Al}$ administration, the number of lysosomes with high electron densities as well as the number of degeneration vacuoles increased (Fig. 2D). At 13 weeks Al administration, the lysosomes with electron density and degeneration vacuoles increased to levels more than those in 9 week administration (Fig. 2E). Under high magnification, evidence of degeneration and swelling of the cytoplasm in some proximal convoluted tubule cells was seen to be similar to that of the 9 week administration group. In addition, it was recognized that the brush borders of proximal convoluted tubule cells disappeared in the degenerative cells. Those results suggested that such cell degeneration caused illness with proteinurea, amino acid-urea, and glycosurea in the kidney. At 17 weeks $\mathrm{Al}$ administration, the lysosomes with electron density and degeneration vacuoles were also observed in the proximal convoluted tubule cells (Fig. 2F). The size of electron-dense lysosomes at this period was the largest among the 9 groups.

\section{EDX microanalysis}

The Al measurement by EDX microanalysis was carried out in the lysosomes with high electron densities in the proximal convoluted tubule cells of the mouse kidney, which were administered with $\mathrm{Al}$ from newborn to 17 weeks after birth. The electron micrograph and the spectrum of EDX microanalysis obtained from the lysosomes and the nuclei in the proximal convoluted tubule cells of the mouse kidney that were administered with $\mathrm{Al}$ for 9 weeks, are
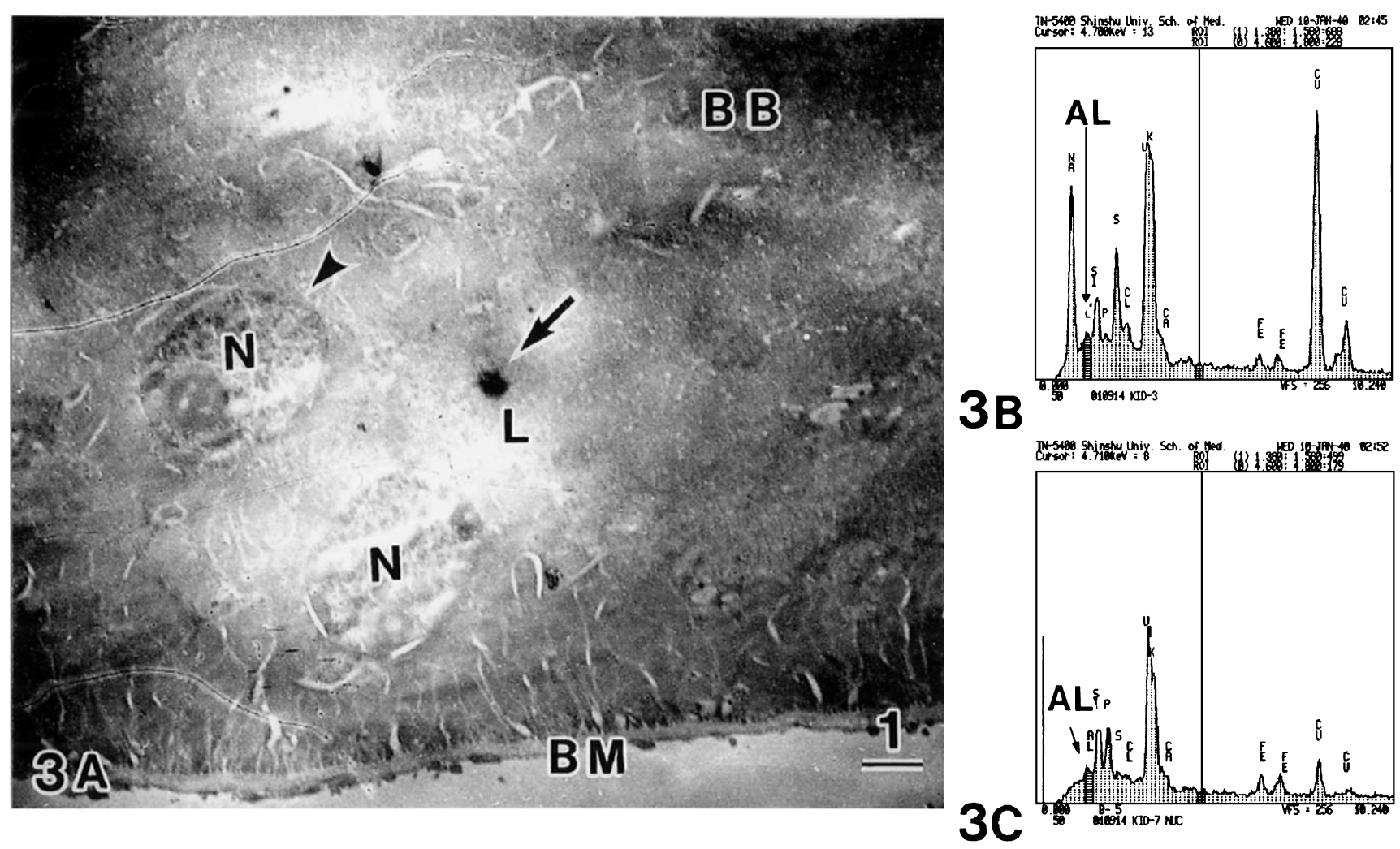

Fig. 3. An electron micrograph and two EDX spectra in a proximal convoluted tubule cell of the kidney with $\mathrm{Al}$ administration for 9 weeks. (A) The lysosome (arrow) and the nucleus (arrow head) were shown in the proximal convoluted tubule cell of the kidney, fixed in glutaraldehyde, embedded in Technovit resin, sectioned at $1 \mu \mathrm{m}$, and stained with uranyl acetate only. L, Lysosome; N, Nucleus; BM, Basement membrane; BB, Brush border. Bar=1 $\mu \mathrm{m}$. (B) EDX spectrum obtained from a highly electron dense lysosome (arrow in A) showing Al peak (arrow). (C) EDX spectrum obtained from the nucleus (arrow head in A) showing Al peak (arrow). 

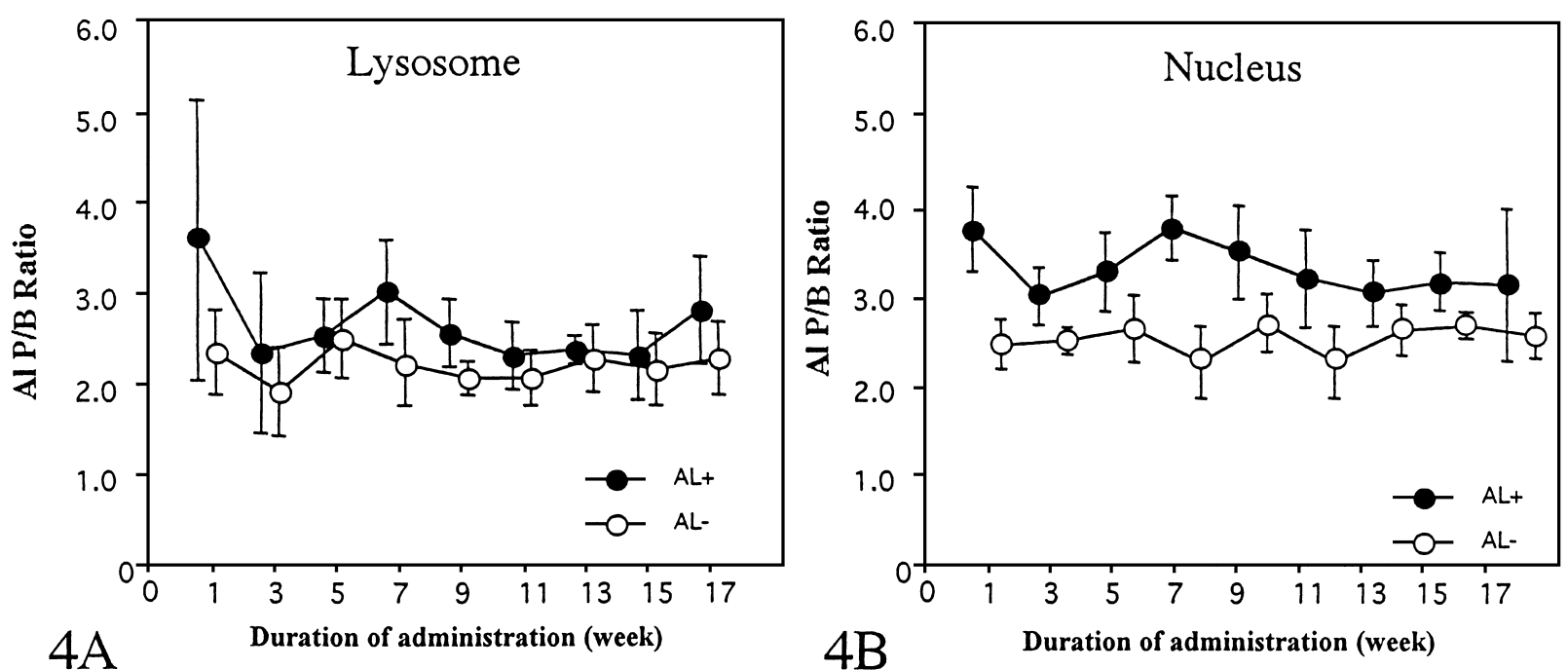

Fig. 4. Transitional changes of $\mathrm{Al} \mathrm{P} / \mathrm{B}$ ratios obtained from the lysosomes and the nuclei of proximal convoluted tubule cells of mice administered with or without $\mathrm{Al}$ for periods from 1 to 17 weeks. (A) Al P/B ratios in the lysosomes. The ratios of the Al administration group were higher than the non-Al administration group. The significant difference by two-way factorial analysis of variance followed by F-test was at $\mathrm{p}<0.0001$. (B) Al $\mathrm{P} / \mathrm{B}$ ratios in the nuclei. The $\mathrm{Al}$ administration group were higher than the non- $\mathrm{Al}$ administration group. The signification difference by the two-way factorial analysis of variance followed by F-test was at $\mathrm{p}<0.048$.

shown in Figure 3. In the specimens for EDX microanalysis, not enough contrast existed to observe ultrastructures by electron microscopy because we did not use either osmium tetroxide for post-fixation or lead citrate for electron staining (Fig. 3A). If we had used both osmium tetroxide and lead citrate in specimens preparation, artifacts would have been produced when elements were analyzed by EDX microanalysis. We were able to detect $\mathrm{Al}$ in this study by selecting and precisely localizing the lysosomes for analyzing $\mathrm{Al}$, which had high electron density without the post-fixation and lead staining. Likewise, the nuclei of the proximal convoluted tubule cells were selected and analyzed.

The EDX spectra obtained from the lysosomes (Fig. 3B) and the nuclei (Fig. 3C) in the proximal convoluted tubule cells showed not only $\mathrm{Al}$ but also sodium $(\mathrm{Na})$, silica $(\mathrm{Si})$, phosphorus $(\mathrm{P})$, sulfur $(\mathrm{S})$, chlorine $(\mathrm{Cl})$, uranium $(\mathrm{U})$, potassium $(\mathrm{K})$, calcium $(\mathrm{Ca})$, iron $(\mathrm{Fe})$, and copper $(\mathrm{Cu})$. There was a lot of $\mathrm{Na}, \mathrm{Si}$, and $\mathrm{Cu}$, in addition to $\mathrm{Al}$ in the lysosome (Fig. 3B), while there were large amounts of $\mathrm{Si}$ and $\mathrm{P}$ in the nucleus (Fig. $3 \mathrm{C}$ ). The elements $\mathrm{K}$ and $\mathrm{U}$ were detected in a complex peak in the spectra by EDX microanalysis. Uranium was used with electron staining for ultrastructural observation. As for $\mathrm{Fe}$ and $\mathrm{Cu}$ in the spectra, they may be artifacts that were driven from the specimen chamber at the periphery of the electron microscope. The transitional changes of $\mathrm{Al} \mathrm{P} / \mathrm{B}$ ratio with administration periods obtained from the EDX microanalysis, in both the lysosomes and the nuclei that were administered with and without $\mathrm{Al}$ administration from newborn to 17 weeks, are shown in Figure 4. Here, the highest peak of $\mathrm{Al} \mathrm{P} / \mathrm{B}$ ratio is suggested to be at the period after $\mathrm{Al}$ administration for 1 week. Comparing the $\mathrm{P} / \mathrm{B}$ ratios of $\mathrm{Al}$ in the lysosomes between the two groups of the experimental animals with $\mathrm{Al}$ and without $\mathrm{Al}$, the former were higher than the latter at respective administration periods (Fig. 4A). The stochastical analysis on the significant differences between the quantities of $\mathrm{Al}$ in the lysosomes of the kidneys of mice in the two experimental groups with and without $\mathrm{Al}$ administration, as well as the transition during the administration, were calculated using factorial design with repeated measure two-way factorial analysis of variance followed by Fisher's PLSD for multi-comparison. The results showed that the significance of $\mathrm{Al}$ administration in the lysosome was at $\mathrm{p}<0.0001$, and the significance of administration periods was at $\mathrm{p}<0.015$. Thus, both the differences were significant at $p<0.015$. The results showed that the significance of $\mathrm{Al}$ administration in the nuclei was at $\mathrm{p}<0.001$, and the significance of administration periods was at $p<0.048$. Thus, both the differences between the nuclei in the two groups were significant at $\mathrm{p}<0.05$.

\section{Discussion}

In the present study, the morphological changes of the lysosomes in the kidneys of mice were observed in the experimental animals to which excess $\mathrm{Al}$ was administered. In addition, EDX microanalysis using thick sections observed by high accelerating voltage electron microscopy at $300 \mathrm{kV}$ confirmed the $\mathrm{Al}$ accumulation in the lysosomes and the nuclei in the proximal convoluted tubule cells of the kidneys of $\mathrm{Al}$ administered mice. It is generally accepted that Al orally administered is absorbed by the gastrointestinal tract and accumulated in various organs of experimental animals [26-28]. When $\mathrm{Al}$ was orally administered to such experimental animals as mice and rats, the concentrations of $\mathrm{Al}$ in the plasma [18] and urine [15, 26-28] rose within $2 \mathrm{hr}$ after administration. The authors also showed that 
administered $\mathrm{Al}$ was accumulated in the duodenum, the liver, and the kidney within a short time by means of biochemical analyses or histochemical stainings [27]. Those data suggested that $\mathrm{Al}$, which was orally administered and absorbed from gastrointestinal tracts, was carried to the various organs through blood circulation and finally excreted into the urine.

Concerning the $\mathrm{pH}$ of the drinking water given to the experimental animals, it is not ideal to use such a low $\mathrm{pH}$ solution as aqueous $\mathrm{AlCl}_{3}$ at $\mathrm{pH}$ 2.5. However, the efficiency of the $\mathrm{Al}$ absorption with low $\mathrm{pH}$ aqueous solutions in the gastrointestinal tracts, as well as the accumulation into the blood and tissues, had already been reported, showing that it was much better than at a higher $\mathrm{pH}$ [26]. Our previous experiment confirmed that some growth failure was seen in the mice treated with $\mathrm{AlCl}_{3}$ administration. Almost all mice were alive during the administration periods until postnatal 17 weeks without any problems.

The morphological changes in the kidney tissues of mice due to prenatal development and aging were already studied by means of light and electron microscopic radioautography using ${ }^{3} \mathrm{H}$-thymidine, ${ }^{3} \mathrm{H}$-uridine, and ${ }^{3} \mathrm{H}-$ glucosamine incorporations in our laboratory $[8,10]$. It was demonstrated that the DNA synthesis, proliferation, and the developments of both renal corpuscles and the uriniferous tubules including proximal convoluted tubule cells, were completed by postnatal day 1 , in contrast to the results that the RNA and glycoprotein syntheses decreased from prenatal stage to postnatal 1 week and still continued until postnatal year 1, which showed the turnovers of these molecules. Thus, the detection of $\mathrm{Al}$ in the proximal convolute tubule cells from postnatal week 1 to 17 in this study was carried out after the morphogenesis was completed in mice.

Previously, many studies reported on applications of EDX microanalysis to biological samples [4, 9, 34]. In those studies, conventional electron microscopy and ultrathin sections at $0.06-0.1 \mu \mathrm{m}$ thicknesses were used with various methods of the fixations. Usually, biological researchers use conventional electron microscopy with ultrathin sections at $0.1 \mu \mathrm{m}$ by EDX microanalysis which is carried out at accelerating voltages of $80-100 \mathrm{kV}$. The reason for using ultrathin sections at $0.1 \mu \mathrm{m}$ thicknesses is that electron beams at accelerating voltages of $80-100 \mathrm{kV}$ can not transmit sections thicker than $0.1 \mu \mathrm{m}$ ultrathin thickness. However, it is obvious that very small amount of any element can be detected more efficiently in thicker sections, which contain many more elements than do thinner sections. We have already reported several studies in which it was suggested that EDX microanalysis using high accelerating voltages and thicker sections could efficiently detect a very small amount of elements such as $\mathrm{Al}, \mathrm{Ag}, \mathrm{Ce}, \mathrm{Zn}, \mathrm{Ca}$, and $\mathrm{S}[11,12,20-22,24,25]$. The utility of using high acceleration voltages by electron microscopic observation of thick biological samples was formerly reported by the present authors [11, 12, 20-22].

On the other hand, in order to detect all the elements contained in the biological samples by EDX microanalysis, some specific fixations, other than conventional chemical fixations such as glutaraldehyde and osumium tetrorxide, should be applied. For detecting electrolyte and insoluble components, freeze fixation followed by freeze-drying or freeze-substitution and embedding in resin without using any water, is necessary $[4,9,23]$. The methods for freeze fixation followed by freeze-drying or freeze-substitution and embedding in resin or freeze-dried cryosections did better at keeping all the elements in the tissues and cells by preventing the washing-away and diffusion of the soluble components, compared with other conventional methods [23]. However, it was ascertained that few elements were preserved with chemical fixation on EDX microanalysis [11]. It was also supposed that some elements bound to the insoluble components were preserved in the biological samples fixed with chemical fixation. In the previous study, it was suggested that $\mathrm{Al}$ conjugated with proteins was preserved in the lysosomes and nuclei [12]. Thus, in the present study, we used chemical fixation for detecting $\mathrm{Al}$ by EDX microanalysis in the kidneys during the administration periods.

As a result of the morphological observations in the present study, changes in the lysosomes of the kidneys by excess $\mathrm{Al}$ administration were found to be similar to those caused by lysosomotropic metals such as $\mathrm{Cu}, \mathrm{Fe}, \mathrm{Hg}, \mathrm{Au}, \mathrm{Tl}$, as reported by De Duve et al. [5] and Schneider et al. [31]. They reviewed the biochemical and morphological changes in the lysosomes caused by lysosomotropic agents, which included not only the metal agents but also various drugs such as antibiotics, phenothiazine derivatives, anti-inflammatory and anti-parasitic drugs. They discovered administered elements such as copper, iron, mercury, gold, thallium, and silica, in the lysososmes of the liver and other organs in humans and other animals. Concerning $\mathrm{Al}$ accumulation, it was shown that overload or depletion of iron affected the uptake of $\mathrm{Al}$ into the sera, urine, and brains of rats [2]. Likewise, human hemodialysis patients who were exposed to an accidental aluminum overload, showed dramatic increases in the proportion of plasma aluminum levels to plasma iron levels [3]. When traces of metals such as aluminum, gallium, indium, zirconium, hafnium, chromium, niobium, uranium, goddinium, gold, nickel, palladium, and platinum were abnormally introduced into experimental animals in vivo or in vitro, it was demonstrated that those metals selectively accumulated in the lysosomes of the convoluted tubule cells of the kidney by EDX microanalysis [1]. Schneider et al. reviewed in detail that such changes of lysosomes were called, 'lysosomal storage disease' [31].

On the other hand, Menkes' disease was known to be a congenital abnormality of copper metabolism [13], while the macular mouse was well known to be a model animal for Menkes' disease. In the macular mouse kidney, similar changes in the lysosomes of the convoluted tubule cells were reported [33]. Thus, Menkes' disease is caused by a copper storage problem in the lysosomes of the kidney. In those studies, the specific lysosomes increased when they were injured by the accumulation of copper $[13,33]$. In the present study on $\mathrm{Al}$ accumulation, the morphological changes of the 
lysosomes in the proximal convoluted tubule cell of the kidney were observed to be similar to those of Menkes' disease [13]. Furthermore, the size and the number of lysosomes observed in the convoluted tubule cells in the kidney changed depending on the administration period when $\mathrm{Al}$ administration was maintained. The $\mathrm{Al}$ contents in the lysosomes and the nuclei in the proximal convoluted tubule cells were directly analyzed by EDX microanalysis in this study. As a result, an important conclusion provided in this study on an $\mathrm{Al}$ accumulation model in experimental animals was that $\mathrm{Al}$ accumulation was directly shown in the lysosomes and nuclei. Aluminum in lysosomes was detected in the proximal convoluted tubule cells of the kidney, and the quantities of $\mathrm{Al}$ increased according to the administration periods. The quantity of $\mathrm{Al}$ in the nuclei also increased according to the administration periods.

It was reported that $\mathrm{Al}$ administration inhibited the lysosomal proton pump in rat liver [38]. The authors confirmed that administered $\mathrm{Al}$ was either combined with proteins and accumulated in the lysosome or that it remained as an electrolyte ingredient in the cytoplasm. It was estimated that $\mathrm{Al}$ of an existing electrolyte ingredient, controlled activity of proton pump in the lysosome of cytoplasm. As the result, the possibility that Al may be obstructed from being taken into the lysosomes was interrupted by excessive $\mathrm{Al}$ incorporation in cytoplasm, which caused hinderance of the formation of Mg-ATP complex in the lysosome membrane. In the present study, the cell injuries of the convoluted tubule cells were observed to advance depending on the $\mathrm{Al}$ administration period; even the quantities of $\mathrm{Al}$ in lysosomes did not increase. As a result of ultrastructural observation, cytoplasm degeneration and the disappearance of brush borders in the proximal convoluted tubule cells of the kidney were seen at 13 weeks after $\mathrm{Al}$ administration. The appearances of large lysosomes, which were seen from 13 to 17 weeks administration with $\mathrm{Al}$, were possibly due to the excess accumulation of $\mathrm{Al}$ in the nuclei, caused the nuclear degeneration, so that perhaps the Al components in the karyoplasm were taken into the lysosomes.

In conclusion, the present study dealt with EDX microanalysis using thick sections and high accelerating voltage electron microscopy detecting $\mathrm{Al}$ accumulation in the proximal convoluted tubule cells of the kidney of mice, which were administered with $\mathrm{Al}$ for short-term periods. The quantities of $\mathrm{Al}$ detected in the lysosomes of convoluted tubule cells of the kidney did not relate to the Al administration period. The significant differences in the quantities of $\mathrm{Al}$ in the lysosomes and nuclei were observed by repeated measurement using two-way factorial analysis of variance followed by Fisher's PLSD for multi-comparison, in which the administration group and the non-administration group were compared. Furthermore, the quantity of Al detected in the nuclei of the convoluted tubule cells of the kidneys of the $\mathrm{Al}$-administered mice showed a correlation with Al administration period.

It was suggested that the EDX microanalysis with thick sections and high accelerating voltage was useful in analyzing metal accumulations in biological samples.

\section{Acknowledgments}

This study was supported in part by a Grant-in-Aid for Scientific Research (No. 0922057, 11922067 and 14922096) from the Ministry of Education, Science and Culture, Japan.

\section{References}

1. Berry, J.-P. (1996) The role of lysosomes in the selective concentration of mineral elements. A microanalytical study. Cell. Mol. Biol. 42; 395-411.

2. Cannata, J. B., Fernández-Soto, I., Fernández-Menendez, M. J., Fernández-Martin, J. L., McGregor, S. J., Brock, J. H. and Halls, D. (1991) Role of iron metabolism in absorption and cellular uptake of aluminum. Kidney Int. 39; 799-803.

3. Caramelo, C. A., Cannata, J. B., Rodeles, M. R., Martin, J. L. F., Mosquera, J. R., Monzú, B., Outeiriño, J., Blum, G., Andrea, C., Farré, A. J. L., Acuña, G., Casado, S. and Hernando, L. (1995) Mechanisms of aluminum-induced microcytosis: lessons from accidental aluminum intoxication. Kidney Int. 47; 164-168.

4. Daimon, T., Mizuhira, V., Ono, M. and Uchida, K. (1983) Elemental composition of the dense bodies of rat platelets determined by electron probe X-ray microanalysis of freezesubstituted sections. Histochemistry 77; 329-337.

5. De Duve, C., De Barsy, T., Poole, B., Trouet, A., Tulkens, P. and Van Hoof, F. (1974) Commentary. Lysosomotropic agents. Biochem. Pharmacol. 23; 2495-2531.

6. Flaten, T. P., Alfrey, A. C., Birchall, J. D., Savory, J. and Yokel, R. A. (1996) Status and future concerns of clinical and environmental aluminum toxicology. J. Toxicol. Environ. Health 48; 527-541.

7. Flaten, T. P. (2001) Aluminium as a risk factor in Alzheimer's disease, with emphasis on drinking water. Brain Res. Bull. 55; 187-196.

8. Hanai, T. and Nagata, T. (1994) Study on the nucleic acid synthesis in the aging mouse kidney by light and electron microscopic radioautography. In "Radioautography in Medicine" ed. by $\mathrm{T}$. Nagata, Shinshu Univ. Press, Matsumoto, pp. 209-214.

9. Hasegawa, H., Mizuhira, V. and Notoya, M. (2000) Microwavestimulated fixation and histochemical application to biological specimens. Acta Histochem. Cytochem. 33; 319-340.

10. Johkura, K. (1996) The aging changes of glycoconjugate synthesis in mouse kidney studied by ${ }^{3} \mathrm{H}$-glucosamine radioautography. Acta Histochem. Cytochem. 29; 57-63.

11. Kametani, K., Ichikawa, R. and Nagata, T. (1998) X-ray microanalysis of the secretory granules in goblet cells of mouse intestinal tracts: change with age. Med. Electron Microsc. 31; 107114.

12. Kametani, K. (2002) Detection of aluminium by energy dispersive X-ray microanalysis at high accelerating voltages with semithin sections of biological sample. J. Electron Microsc. 51; 265274.

13. Kodama, H., Abe, T., Takama, M., Takahashi, I., Kodama, M. and Nishimura, M. (1993) Histochemical localization of copper in the intestine and kidney of macular mice: light and electron microscopic study. J. Histochem. Cytochem. 41; 1529-1535.

14. Liu, J., Nordberg, G. F. and Frech, W. (1996) Aluminium accumulation in some tissues of rats with compromised kidney function induced by cadmium-metallothionein. Pharmacol. Toxicol. 78; 289-295.

15. Maitani, T., Kubota, H., Hori, N., Yoshihira, K. and Takeda, M. (1994) Distribution and urinary excretion of aluminium injected 
with several organic acids into mice: relationship with chemical state in serum studied by the HPLC-ICP method. J. Appl. Toxicol. $14 ; 257-261$

16. Marshall, A. T., Schroen, C. and Condron, R. J. (1994) X-ray microanalysis of renal proximal tubules in cadmium-treated rats. J. Submicrosc. Cytol. Pathol. 26; 59-66.

17. McLachlan, D. R. (1986) Aluminum and Alzheimer's disease. Neurobiol. Aging 7; 525-532.

18. Molitoris, B. A., Froment, D. H., Mackenzie, T. A., Huffer, W. H. and Alfrey, A. C. (1989) Citrate: a major factor in the toxicity of orally administered aluminum compounds. Kidney Int. 36; 949 953.

19. Mullins, J. E. and Fuentealba, I. C. (1998) Immunohistochemical detection of metallothionein in liver, duodenum and kidney after dietary copper-overload in rats. Histol. Histopathol. 13; 627-633.

20. Nagata, T. (1988) X-ray microanalysis of biological specimens with $400 \mathrm{kV}$ electron microscopes. J. Electron Microsc. 37; 9595.

21. Nagata, T. (1991) Electron microscopic radioautography and analytical electron microscopy. J. Clin. Electron Microsc. 24; 441-442.

22. Nagata, T. (1993) Quantitative analysis of histochemical reactions: Image analysis of light and electron microscopic radioautograms. Acta Histochem. Cytochem. 26; 281-291.

23. Nagata, T. (1994) Electron microscopic radioautography with cryo-fixation and dry-mounting procedure. Acta Histochem Cytochem. 27; 471-489.

24. Olea, M. T. and Nagata, T. (1991) X-ray microanalysis of cerium in mouse spleen cells demonstrating acid phosphatase activity using high voltage electron microscope. Cell. Mol. Biol. 37; 155163.

25. Ono, S. (1991) Electron microscopy and electron probe X-ray microanalysis of human lumber yellow ligament by frozen-dried cryosections. J. Clin. Electron Microsc. 24; 377-388.

26. Partridge, N. A., Regnier, E. R., Reed, W. M., White, J. L. and Hem, S. L. (1992) Contribution of soluble aluminium species to absorption of aluminium from the rat gut in situ. Clin. Sci. 83; 425-430.

27. Quartley, B., Esselmont, G., Taylor, A. and Dobrota, M. (1993)
Effect of oral aluminium citrate on short-term tissue distribution of aluminium. Food Chem. Toxicol. 31; 543-548.

28. Recker, R. R., Blotcky, A. J., Leffler, J. A. and Rack, E. P. (1977) Evidence of aluminum absorption from the gastrointestinal tract and bone deposition by aluminum carbonate ingestion with normal renal function. J. Lab. Clin. Med. 90; 810-815.

29. Savory, J., Exley, C., Forbes, W. F., Huang, Y., Joshi, J. G., Kruck, T., McLachlan, D. R. and Wakayama, I. (1996) Can the controversy of the role of aluminum in Alzheimer's disease be resolved? What are the suggested approaches to this controversy and methodological issues to be considered? J. Toxicol. Environ. Health 48; 615-635.

30. Schmid, K. W., Morgan, J. M., Öfner, D., Hittmair, A., Haywood, S. and Jasani, B. (1993) Quantitative immunohistochemical evaluation by image analysis of metallothionein in copper-loaded rat kidney. J. Histochem. Cytochem. 41; 727-731.

31. Schneider, P., Korolenko, T. A. and Busch, U. (1997) A review of drug-induced lysosomal disorders of the liver in man and laboratory animals. Microsc. Res. Tech. 36; 253-275.

32. Sumi, Y., Itoh, M. T., Murasaki, T. and Suzuki, T. (1996) Histochemical staining of cadmium with 2-(8-quinolylazo)-4,5diphenylimidazole. Histochem. Cell Biol. 106; 223-227.

33. Suzuki-Kurosaki, M., Okabe, M. and Kurasaki, M. (1997) Copper-metallothionein in the kidney of macular mice: a model for Menkes disease. J. Histochem. Cytochem. 45; 1493-1501.

34. Takaya, K. (1982) Electron microscopy of the mouse cerebral cortex in unstained, fresh air-dried spreads and fresh frozen dried ultrathin sections. Okajimas Folia Anat. Jpn. 58; 797-808.

35. Wilhelm, M., Jäger, D. E. and Ohnesorge, F. K. (1990) Aluminium toxicokinetics. Pharmacol. Toxicol. 66; 4-9.

36. Yokel, R. A. and McNamara, P. J. (2001) Aluminium toxicokinetics: an update minireview. Pharmacol. Toxicol. 88; 159-167.

37. Yoshizuka, M., McCarthy, K. J., Kaye, G. I. and Fujimoto, S. (1990) Cadmium toxicity to the cornea of pregnant rats: Electron microscopy and X-ray microanalysis. Anat. Rec. 227; 138-143.

38. Zatta, P., Taylor, A., Zambenedetti, P., Milacic, R. and dell'Antone, P. (2000) Aluminum inhibits the lysosomal proton pump from rat liver. Life Sci. 66; 2261-2266. 